\title{
A long-life lithium-oxygen battery via a molecular quenching/mediating mechanism
}

\section{Jinqiang Zhang}

University of Technology Sydney https://orcid.org/0000-0001-5476-0134

Yufei Zhao

University of New South Wales

\section{Bing Sun}

University of Technology Sydney https://orcid.org/0000-0002-4365-486X

\section{Yuan Xie}

University of Technology Sydney

\section{Anastasia Tkacheva}

University of Technology Sydney

\section{Feilong Qiu}

Nanjing University

\section{Ping He}

Nanjing University https://orcid.org/0000-0002-1498-8203

Haoshen Zhou

Nanjing University

\section{Kang Yan}

University of Technology Sydney

\section{Xin Guo}

University of Technology Sydney

\section{Shijian Wang}

University of Technology Sydney

\section{Andrew McDonagh}

University of Technology Sydney

\section{Zhangquan Peng}

Dalian Institute of Chemical Physics

Jun Lu

Argonne National Laboratory https://orcid.org/0000-0003-0858-8577

Guoxiu Wang ( $\nabla$ Guoxiu.Wang@uts.edu.au )

University of Technology Sydney https://orcid.org/0000-0003-4295-8578 
Keywords: lithium-oxygen battery, superoxide radical quencher, redox mediator, mobile catalyst, molecular design.

Posted Date: June 3rd, 2021

DOI: https://doi.org/10.21203/rs.3.rs-534571/v1

License: (1) This work is licensed under a Creative Commons Attribution 4.0 International License. Read Full License

Version of Record: A version of this preprint was published at Science Advances on January 21st, 2022. See the published version at https://doi.org/10.1126/sciadv.abm1899. 


\section{Abstract}

Lithium-oxygen $\left(\mathrm{Li}^{-} \mathrm{O}_{2}\right)$ batteries have drawn intensive attention owing to their exceptionally high theoretical specific energy. However, their further advancement has been significantly hindered by challenges including low discharge capacity, poor energy efficiency, severe parasitic reactions, etc. Here, we report a highly Li- $\mathrm{O}_{2}$ battery operated via a new quenching/mediating mechanism that relies on the direct chemical reactions between a versatile molecule and superoxide radical/ $\mathrm{Li}_{2} \mathrm{O}_{2}$ nanoparticles. The battery exhibits a 46-fold increase of discharge capacity, a low charge over-potential of $0.7 \mathrm{~V}$, and an ultralong cycle life $>1400$ cycles. The tailor-designed organic molecule features two redox mediatoractive 2,2,6,6-tetramethyl-1-piperidinyloxy (TEMPO) moieties bridged by a quenching-active perylene diimide (PDI) backbone. The PDI-TEMPO molecule not only acts as a soluble redox mediator to catalyze both discharge and charge reactions, but also serves as a reusable superoxide radical quencher to chemically react with superoxide species generated during the operation of $\mathrm{Li}-\mathrm{O}_{2}$ batteries, leading to the formation of $\mathrm{Li}_{2} \mathrm{O}_{2}$ nanoparticles which are much easier to decompose than the conventional toroidalshaped $\mathrm{Li}_{2} \mathrm{O}_{2}$. The all-in-one molecule as a multifunctional additive can tackle various issues of parasitic reactions associated with superoxide radicals, singlet oxygen, high over-potentials, and lithium corrosion, beyond the mere combination of PDI and TEMPO moieties' functionalities. The molecular design of multifunctional additives combining the capabilities of redox mediators, superoxide radical quencher and beyond opens a new avenue for developing high-performance $\mathrm{Li}^{\mathrm{i}} \mathrm{O}_{2}$ batteries.

\section{Introduction}

Lithium-oxygen $\left(\mathrm{Li}^{-} \mathrm{O}_{2}\right)$ batteries have the highest theoretical specific energy among all-known battery chemistries and are deemed a disruptive technology if a practical device could be realized. ${ }^{1-5}$ Typically, a non-aqueous $\mathrm{Li}_{-} \mathrm{O}_{2}$ battery consists of a lithium metal anode separated from a porous oxygen cathode by $\mathrm{a} \mathrm{Li}^{+}$conducting electrolyte, and its operation relies on the stripping and plating of lithium on the negative electrode and the formation and decomposition of $\mathrm{Li}_{2} \mathrm{O}_{2}$ on the positive electrode. ${ }^{6}$ However, current $\mathrm{Li}-\mathrm{O}_{2}$ batteries suffer from significant challenges including low discharge capacity, poor round-trip efficiency, severe parasitic reactions, etc.

Toward solving these challenges and unlocking the energy capabilities of $\mathrm{Li}^{\mathrm{i}} \mathrm{O}_{2}$ electrochemistry, a great deal of research effort has been devoted to a fundamental understanding of the reactions and processes underpinning the operation of $\mathrm{Li}-\mathrm{O}_{2}$ batteries. It has been established that the discharge of a $\mathrm{Li}-\mathrm{O}_{2}$ battery proceeds with the oxygen reduction reaction (ORR) generating superoxide species (superoxide radicals $\mathrm{O}_{2}{ }^{*}$-/lithium superoxide $\mathrm{LiO}_{2}$ ) that can either adsorb on the cathode surface followed by a surface mechanism or dissolve in the electrolyte solution followed by a solution mechanism. ${ }^{7,8}$ The surface mechanism often produces $\mathrm{Li}_{2} \mathrm{O}_{2}$ with a thin layer morphology (a few nanometers in thickness) that rapidly passivates the cathode surface and leads to a low discharge capacity and a low rate capability. On the contrary, the solution mechanism usually generates $\mathrm{Li}_{2} \mathrm{O}_{2}$ with a toroidal shape (up to a few 
microns in diameter) in the electrolyte solution and can support a high discharge capacity and a high rate capability. However, toroidal-shaped $\mathrm{Li}_{2} \mathrm{O}_{2}$ is not sufficiently close to the cathode surface and major part of the $\mathrm{Li}_{2} \mathrm{O}_{2}$ toroid is beyond the e-tunnelling range during the charge process. Therefore, the oxidation of these $\mathrm{Li}_{2} \mathrm{O}_{2}$ proceeds through mechanisms beyond simply one-step electrochemical oxidation, including direct $2 \mathrm{e}^{-}$oxidation, ${ }^{7}$ solid-solution oxidation $\left(\right.$ via $\left.\mathrm{Li}_{2-\mathrm{x}} \mathrm{O}_{2}\right),{ }^{9,10}$ and step-wise oxidation $\left(\right.$ via $\left.\mathrm{LiO}_{2}\right) .{ }^{11}$ Recent studies suggest that singlet oxygen $\left({ }^{1} \mathrm{O}_{2}\right)$ may also involve in discharge and charge processes, during the disproportionation reaction of $\mathrm{LiO}_{2}$ species and in the $1 \mathrm{e}^{-}$oxidation of $\mathrm{LiO}_{2}$ intermediates, and $2 \mathrm{e}^{-}$ oxidation of solid $\mathrm{Li}_{2} \mathrm{O}_{2} .{ }^{12}$ Parasitic reactions occur inevitably during both discharge and charge processes. The parasitic reactions during discharge are mainly associated with the chemical attack of battery components (electrolytes and electrodes) by the reactive oxygen species $\left(\mathrm{O}_{2}{ }^{\circ}, \mathrm{LiO}_{2}, \mathrm{Li}_{2} \mathrm{O}_{2}\right.$ and $\left.{ }^{1} \mathrm{O}_{2}\right) \cdot{ }^{13,14}$ However, the parasitic reactions during the charge process are more than chemical attack. Besides the chemical decomposition of battery components by reactive oxygen species generated during charging, the high voltage ( $>4 \mathrm{~V}$ ) frequently applied during charging can also electrochemically oxidize the electrolyte and cathode materials, particularly in the presence of $\mathrm{Li}_{2} \mathrm{O}_{2} \cdot{ }^{15-17}$

Many strategies have been devised to increase discharge capacity, lower charge over-potential, and alleviate parasitic reactions. These include using high donor number solvents and salts with the ability to decrease the reactivity (acidity) of $\mathrm{Li}^{+}$, certain additives that can stabilize superoxide radicals, and redox mediators that can relay electrons between cathode surface and dissolved oxygen. ${ }^{18-21}$ These approaches have been employed to promote $\mathrm{Li}_{2} \mathrm{O}_{2}$ formation in the electrolyte solution rather on the cathode surface and therefore increase the discharge capacity, among which the redox mediators demonstrate prominent performance. Nevertheless, the discharge product $\mathrm{Li}_{2} \mathrm{O}_{2}$ is difficult to be oxidized owing to its poor physical contact with the cathode surface and its intrinsically low electronic and ionic conductivity. ${ }^{22,23}$ Oxygen evolution reaction (OER) redox mediators have also been proposed to efficiently oxidize $\mathrm{Li}_{2} \mathrm{O}_{2}$. The oxidized form of redox mediators generated on the cathode surface can diffuse to the $\mathrm{Li}_{2} \mathrm{O}_{2}$ in the electrolyte solution and oxidize $\mathrm{Li}_{2} \mathrm{O}_{2}$ to $\mathrm{O}_{2}$ with itself being regenerated. ${ }^{24-31}$ Because the OER redox mediators often have a redox potential that is much lower than the potential required to charge a Li- $\mathrm{O}_{2}$ cell (usually $>4.0 \mathrm{~V}$ ), the energy efficiency of the $\mathrm{Li}^{-} \mathrm{O}_{2}$ battery can be improved accordingly. Due to the low charging voltage, the decomposition of battery components during charging can be alleviated. Furthermore, to reduce the parasitic reactions caused by the attack of the reactive oxygen species, more stable electrolytes and cathode materials need to be employed to construct $\mathrm{Li}^{\mathrm{i}} \mathrm{O}_{2}$ batteries. ${ }^{32-35} \mathrm{In}$ addition, a few ORR redox mediators that can promote oxygen reduction to $\mathrm{Li}_{2} \mathrm{O}_{2}$ via a benign intermediate instead of the very reactive superoxide radicals have been used to mitigate the parasitic reactions. ${ }^{20,36-43}$ Similarly, molecular ${ }^{1} \mathrm{O}_{2}$ quencher has also been used to deactivate the reactivity of ${ }^{1} \mathrm{O}_{2}$, which also contributes to the suppression of overall parasitic reactions. ${ }^{44,45}$ However, the combination of these functional molecules in one cell is rarely reported. The intrinsic reactivity of each component can easily conflict with another, leading to the weakening or even deactivating of the functionalities of these individual molecules. 
All in all, to realize a high discharge capacity, a low charge overpotential, and less parasitic reactions for $\mathrm{Li}-\mathrm{O}_{2}$ batteries, it is desirable to have a multifunctional catalyst that simultaneously has the capabilities of ORR redox mediators, OER redox mediators, and superoxide radical quencher. However, the design and synthesis of such all-in-one molecules has not been reported. Here, we rationally designed and successfully synthesized a multifunctional superoxide radical quencher by grafting two redox mediatoractive 2,2,6,6-tetramethyl-1-piperidinyloxy (TEMPO) functional groups to a quenching-active perylene diimide (PDI) backbone. The as-synthesized N,N'-di-(2,2,6,6-tetramethyl-1-oxyl-4-piperidinyl)-perylene3,4,9,10-tetracarboxylic diimide (PDI-TEMPO) molecules can not only chemically quench superoxide species generated during discharge and charge processes to suppress the generation of ${ }^{1} \mathrm{O}_{2}$, but also act as a redox mediator to efficiently catalyze the formation and decomposition of $\mathrm{Li}_{2} \mathrm{O}_{2}$ in the electrolyte solution and lower the discharge and charge overpotentials of $\mathrm{Li}_{-} \mathrm{O}_{2}$ batteries. The synergistic effect of TEMPO and PDI moieties can also induce more functionalities to minimize parasitic reactions such as preventing the corrosion of lithium anode. When adding PDI-TEMPO in the electrolyte, the $\mathrm{Li}^{\mathrm{i}} \mathrm{O}_{2}$ batteries proceed via an alternative chemical quenching mechanism, which achieves higher discharge capacity, lower charge over-potential, less parasitic reaction, and longer cycle life.

\section{The synthesis and characterization of PDI-TEMPO molecules}

The PDI-TEMPO reagent was synthesized by reacting 4-amino-2,2,6,6-tetramethylpiperidine with perylene3,4,9,10-tetracarboxylic dianhydride, followed by an oxidation process (Figure S1a), yielding reddishpurple powders as the final product. ${ }^{46,47}$ The PDI-TEMPO shows a good solubility in common electrolyte solvents used in $\mathrm{Li}-\mathrm{O}_{2}$ batteries, including diethylene glycol dimethyl ether (DEGDME) and dimethyl sulfoxide (DMSO) (Figure S1b). The molecular structures of PDI-TEMPO and intermediates were confirmed by several spectroscopic techniques including ultraviolet-visible spectroscopy (UV-Vis), mass spectrometry (MS), Fourier-transform infrared (FTIR) spectroscopy, and electron paramagnetic resonance (EPR) spectroscopy (Figure S2). The strong absorption bands of amide at 1650 and $1680 \mathrm{~cm}^{-1}$ in the FTIR spectra indicate that the TEMPO functional groups have been covalently linked to the PDI backbone (Figure S2c). Fluorescence spectroscopy shows that the TEMPO radicals in PDI-TEMPO molecules quench the fluorescence of the PDI backbones, further verifying the successful synthesis of PDI-TEMPO molecules (Figure S3). ${ }^{48}$

The PDI-TEMPO molecule features two TEMPO moieties bridged by a conjugated PDI backbone (Figure 1a). The multifunctional PDI-TEMPO molecule is specifically designed to enhance the electrochemical performance and reduce parasitic reactions of $\mathrm{Li}_{2} \mathrm{O}_{2}$ batteries (Figure S4). The conjugated PDI backbone is an efficient electron acceptor to react with $\mathrm{O}_{2}{ }^{--}$and can behave as a quencher by quenching the reactivity of $\mathrm{O}_{2}-46$ The TEMPO moieties can be electrochemically reduced and oxidized, and therefore can be used as a soluble redox mediator for promoting both discharge and charge reactions in $\mathrm{Li}-\mathrm{O}_{2}$ batteries. The chemical grafting of these moieties via chemical bonds integrates these functionalities in one molecule and enables the intermolecular interactions, which may stabilize these moieties and present individual properties without interference. The chemical bondings between these two functional moieties 
can not only efficiently overcome the drawback of each group (insolubility for PDI-based materials and irreversible n-doping of TEMPO molecules), but also provide additional functionalities beyond the simple

combinations. These synergistic properties can also efficiently suppress the generation of ${ }^{1} \mathrm{O}_{2} \cdot{ }^{45,49,50} \mathrm{PDI}$ TEMPO molecules have a sterically twisted structure, owing to the steric interactions between the conjugated PDI backbone and bulky TEMPO moieties (Figure 1b). Such unique molecular architecture can maintain optimal Van Der Waals forces via $\pi-\pi$ interaction between conjugated PDI backbone and the basal plane of the graphitic carbon cathode, which prohibited its diffusion to the lithium anode. ${ }^{51}$

\section{Redox behaviour of PDI-TEMPO molecules}

The redox behaviour of PDI-TEMPO has been examined using a glassy carbon (GC) electrode in DEGDME electrolyte. As shown in the cyclic voltammetry (CV) results in Figure 1c, PDI-TEMPO shows three pairs of redox peaks in the voltage range of $1.8 \mathrm{~V}$ to $4.4 \mathrm{~V}$. Two pairs of redox peaks (labelled by $a, a^{\prime}, a n d ~ b, b^{\prime}$ ) are assigned to the reversible reduction and oxidation of TEMPO moieties, respectively, which is consistent with previous reports. ${ }^{39,52,53}$ The third pair of redox peaks started at $\sim 2.3 \mathrm{~V}$ originate from the electrochemistry of the PDI backbone, where the corresponding oxidation peak merges with the oxidation peak of reduced TEMPO moieties, causing the merged peak position to downshift from $3.0 \mathrm{~V}$ (the oxidation potential of reduced TEMPO moieties) to $2.5 \mathrm{~V} .{ }^{54}$ These redox pairs are demonstrated highly reversible, showing no visible decay after three cycles (Figure S5a). Even after 25 cycles in oxygen, the characteristic redox peaks remain in the following scan in the argon atmosphere, further verifying the high stability of these redox pairs (Figure S5b).

The electrochemistry of PDI-TEMPO has also been studied by in-situ UV-Vis spectroscopy (Figure $1 \mathrm{~d}$ and Figure S6). During the potential scan from $3.0 \mathrm{~V}$ to $1.8 \mathrm{~V}$, the absorption band in the range of 250 to 350 $\mathrm{nm}$ associated with the TEMPO moieties gradually decreased, indicating that TEMPO moieties were reduced (Figure S6a). Simultaneously, the absorption band in the range of 450 to $550 \mathrm{~nm}$ associated with the pristine PDI backbone decreased and the absorption at $700 \mathrm{~nm}$ from reduced PDI backbone increased (Figure S6b). The in-situ UV-Vis spectroscopic study provides direct evidence that the PDI backbone has also been reduced following the reduction of the TEMPO moieties. Both reduction reactions are highly reversible because all absorption bands are recovered to their original states at the end of the reverse potential scan from 1.8 to $3.1 \mathrm{~V}$ (Figure S6c-d). When the potential is further scanned to $3.6 \mathrm{~V}$ and beyond, the absorption band of the oxidized TEMPO moieties $(250-350 \mathrm{~nm})$ increases accordingly (Figure S6e), and recovers to their original intensities when the voltage is reversed to $3.0 \mathrm{~V}$ (Figure S6g). The peaks associated with the PDI backbone does not change because no redox reaction of PDI takes place in this potential range of 3.0 - 4.5 V (Figure S6f and S6h). These results unambiguously confirm that there are three highly reversible redox reactions of PDI-TEMPO in the operation potential range of Li$\mathrm{O}_{2}$ batteries.

The redox behaviour of PDI-TEMPO molecules has been further elucidated through density functional theory (DFT) calculations. Figure S7 shows the visualized lowest unoccupied molecular orbital (LUMO), highest occupied molecular orbital (HOMO) and singly occupied molecular orbital (SOMO) of PDI-TEMPO 
molecules. The HOMO is fully occupied with electrons, and thereby can only provide electrons. Its energy level corresponds to the oxidation potential. Similarly, the LUMO can only accept electrons, and its energy level relates to the reduction potential. The SOMO, on the other hand, is partially occupied by one electron, therefore can both provide and accept electrons, and its energy level represents both oxidation and reduction potentials. Furthermore, the positions of the molecular orbitals also represent the possible sites where the redox reactions are most likely to occur. As shown in the left panel in Figure S7a, both LUMO and HOMO are distributed on TEMPO moieties of PDI-TEMPO, suggesting that the initial oxidation and reduction reactions of PDI-TEMPO are based on reversible redox reactions of TEMPO moieties. Similarly, as presented in the right panel in Figure S7a, the SOMO of the oxidized PDI-TEMPO (PDI-TEMPO ${ }^{+}$) is only distributed in TEMPO moieties, revealing that only TEMPO moieties are capable of being reduced (oxidized TEMPO moiety) and oxidized (neutral TEMPO moiety) at this stage. The SOMO of the reduced PDI-TEMPO (PDI-TEMPO-) in the middle panel in Figure S7a mainly locate on the PDI core and one TEMPO moiety. This designates that the further reduction of PDI-TEMPO would occur on the PDI backbone, while the oxidation reaction would take place on the reduced TEMPO moiety. The DFT calculation results are consistent with the electrochemical studies (Figure 1c-d).

The oxidative and reductive capability of PDI-TEMPO molecules shown in Figure S7b reveals that the SOMO of the reduced PDI-TEMPO (-1) is higher than the LUMO of $\mathrm{O}_{2}$. Therefore, the reduced PDI-TEMPO can reduce $\mathrm{O}_{2}$ during the discharge process. The SOMO of the oxidized PDI-TEMPO (+1) is significantly lower than the $\mathrm{HOMO}$ of $\mathrm{Li}_{2} \mathrm{O}_{2}$, suggesting it can decompose $\mathrm{Li}_{2} \mathrm{O}_{2}$ during the charge process. Thus, PDITEMPO molecules can boost both discharge and charge processes of $\mathrm{Li}^{-} \mathrm{O}_{2}$ batteries owing to their unique redox properties.

\section{PDI-TEMPO molecules as a highly efficient $\mathrm{O}_{2}{ }^{--}$quencher}

PDI-TEMPO with the unique molecular and electronic structure can not only facilitate the formation and decomposition of $\mathrm{Li}_{2} \mathrm{O}_{2}$ via the redox-active TEMPO functional moieties, but also effectively chemically eliminate $\mathrm{O}_{2}{ }^{--}$through the conjugated PDI backbone as a $\mathrm{O}_{2}{ }^{--}$quencher. Thus, the parasitic reactions originated from $\mathrm{O}_{2}{ }^{-{ }^{-}}$are expected to be significantly suppressed. We verified this hypothesis by dissolving potassium superoxide $\left(\mathrm{KO}_{2}\right)$ in the organic solvents, simulating the formation of $\mathrm{O}_{2}{ }^{- \text {- }}$ during the discharge process. UV-Vis spectra were collected to monitor reactions between $\mathrm{O}_{2}{ }^{-{ }^{-}}$and PDI-TEMPO molecules. ${ }^{55}$ We used DMSO as the solvent due to the relatively high solubility of $\mathrm{O}_{2}{ }^{--}$species in DMSO. After adding PDI-TEMPO into the $\mathrm{KO}_{2}$-saturated DMSO, the UV-Vis absorption band corresponding to the original PDITEMPO (PDIO-TEMPO, 450 - $550 \mathrm{~nm}$ ) vanished immediately, and the band associated with the reduced PDI backbone (PDI-TEMPO, $700 \mathrm{~nm}$ ) appeared initially but decreased with time (Figure 1e). Meanwhile, a series of absorption peaks in the range of $500-650 \mathrm{~nm}$ emerged and remained. These newly formed peaks correspond to the reduced PDI backbone with the acceptance of two electrons (PDI ${ }^{2}$-TEMPO) ${ }^{46}$ This reduction process is accompanied by a colour change of the solution from red to brown and finally blue (Figure S8). Therefore, the PDI backbone can be easily reduced by $\mathrm{O}_{2}{ }^{\circ}$. After adding lithium salt 
(LiTFSI) in the aforementioned reduced PDI-TEMPO solution, the UV absorption associated with the PDI ${ }^{2-}$ TEMPO species gradually vanished, while the peaks corresponding to PDI ${ }^{0}-{ }^{-}$EMPO and PDI-TEMPO reappeared (Figure 1f). This phenomenon indicates that the reduced PDI backbone can be easily oxidized by $\mathrm{O}_{2}{ }^{--}$when lithium salt is present. This mechanism was further confirmed by EPR studies. The EPR peaks generated from the combination of 5,5-dimethyl-1-pyrroline $\mathrm{N}$-oxide (DMPO) and $\mathrm{O}_{2}{ }^{\circ-}$ gradually disappeared after adding PDI-TEMPO and lithium salt (Figure S9). The chemical reactions between PDITEMPO and $\mathrm{O}_{2}{ }^{-*}$ are proposed as below:

$$
\begin{aligned}
& P D I^{0}-T E M P O+O_{2}^{-} \rightarrow P^{-} I^{-}-T E M P O+O_{2} \\
& P D I^{-}-T E M P O+O_{2}^{-} \rightarrow P^{2-}-T E M P O+O_{2} \\
& P D I^{2-}-T E M P O+O_{2}^{-}+2 L^{+} \rightarrow P D I^{-}-T E M P O+L_{2} \mathrm{O}_{2} \\
& P D I^{-}-T E M P O+O_{2}^{-}+2 \mathrm{Li}^{+} \rightarrow P D I^{0}-T E M P O+\mathrm{Li}_{2} \mathrm{O}_{2}
\end{aligned}
$$

(Equation 1)

(Equation 2)

(Equation 3)

(Equation 4)

Overall reaction:

$2 \mathrm{O}_{2}^{-}+2 \mathrm{Li}^{+} \rightarrow \mathrm{Li}_{2} \mathrm{O}_{2}+\mathrm{O}_{2}$
(Equation 5)

Based on the above experimental results, PDI-TEMPO molecules are confirmed to be a reusable soluble $\mathrm{O}_{2}{ }^{-*}$ quencher, which efficiently eliminates $\mathrm{O}_{2}{ }^{-\cdots}$ by chemically reacting with $\mathrm{O}_{2}{ }^{-\cdots}$ to form $\mathrm{Li}_{2} \mathrm{O}_{2}$. As a result, the $\mathrm{O}_{2}{ }^{-\cdots}$ species will be immediately consumed once they are generated, and the parasitic reactions induced by $\mathrm{O}_{2}{ }^{--}$will be significantly diminished. Furthermore, the multi-step chemical reactions between $\mathrm{O}_{2}{ }^{\circ-}$ and PDI-TEMPO detour around the self-disproportion reactions of $\mathrm{O}_{2}{ }^{-\cdots}\left(\mathrm{LiO}_{2}\right)$, which significantly suppresses the generation of ${ }^{1} \mathrm{O}_{2}$, eliminating parasitic reactions associated with ${ }^{1} \mathrm{O}_{2}$ as well (Figure S4). ${ }^{45,49,50}$ The deactivation of $\mathrm{O}_{2}{ }^{--}$by PDI-TEMPO has been further demonstrated by monitoring the reaction of $\mathrm{KO}_{2}$ and DEGDME electrolyte for one week (Figure S10). The FTIR spectra of the DEGDME electrolyte containing PDI-TEMPO show no obvious change after a one-week reaction, suggesting no detectable parasitic reactions between $\mathrm{O}_{2}{ }^{--}$and DEGDME solvent. However, the FTIR spectrum of the control sample (no PDI-TEMPO) shows an increase of peak at $1650 \mathrm{~cm}^{-1}$, which signifies the formation of $\mathrm{C}=\mathrm{O}$, due to attack by active oxygen species. Therefore, PDI-TEMPO in the electrolyte can simultaneously diminish parasitic reactions and promote the formation of $\mathrm{Li}_{2} \mathrm{O}_{2}$.

\section{The discharge behaviour of $\mathrm{Li}^{-} \mathrm{O}_{2}$ batteries with PDI-TEMPO molecules}

The electrochemistry of PDI-TEMPO was examined with CV using a GC electrode in an electrolyte cell. As shown in Figure S11, the ORR peak current in the PDI-TEMPO electrolyte is much higher than that in the bare DEGDME electrolyte. This clearly corroborates the PDI-TEMPO's capability of facilitating the discharge process. Similar results have also been obtained with a $\mathrm{Li}-\mathrm{O}_{2}$ cell containing a carbon paper positive electrode and a lithium foil negative electrode (Figure S12-13). Figure 2a shows the discharge- 
charge profiles of a Li- $\mathrm{O}_{2}$ cell with a cut-off voltage of $2.0 \mathrm{~V}$ and $4.6 \mathrm{~V}$. The cell with PDI-TEMPO electrolyte delivers a specific capacity of $4.5 \mathrm{mAh} \mathrm{cm}{ }^{-2}$, which is over 46 times higher than that of the cell with bare DEGDME electrolyte (less than $0.1 \mathrm{mAh} \mathrm{cm}^{-2}$, Figure 2a and S14). It is worth noting that the same configurated cell with PDI-TEMPO electrolyte operated in an argon atmosphere only provides a specific capacity of $0.02 \mathrm{mAh} \mathrm{cm}^{-2}$ (Figure S15), which is negligible compared with the capacity obtained in the oxygen atmosphere. Therefore, the high specific capacity should be entirely ascribed to the reversible formation and decomposition of $\mathrm{Li}_{2} \mathrm{O}_{2}$ (Figure S16-17), instead of the redox reaction of PDITEMPO dissolved in the electrolyte.

The morphologies of discharged $\mathrm{Li}_{2} \mathrm{O}_{2}$ on the carbon paper electrode after the first discharge were characterized by scanning electron microscopy (SEM). Comparing to the pristine morphology in Figure $2 \mathrm{~b}$, only a small amount of discharge products are observed on carbon fibres when discharged in the bare DEGDME electrolyte (Figure 2c-d). On the contrary, a large quantity of $\mathrm{Li}_{2} \mathrm{O}_{2}$ was generated on carbon fibres in the PDI-TEMPO electrolyte (Figure 2e-f). The cells with PDI-TEMPO electrolyte produced $\mathrm{Li}_{2} \mathrm{O}_{2}$ nanoparticle as the discharge product, which is different from the toroidal-shaped $\mathrm{Li}_{2} \mathrm{O}_{2}$ commonly obtained through a solution mechanism (Figure S18). ${ }^{56,57}$ This indicates that the discharge process may proceed via a different mechanism. We propose a chemical quenching process of $\mathrm{O}_{2}{ }^{-}$by PDI-TEMPO molecules. ${ }^{58}$ As schematically shown in Figure $2 \mathrm{~g}$, the discharge of the $\mathrm{Li}-\mathrm{O}_{2}$ cell is initiated by the reduction of TEMPO moieties, which reacts with oxygen molecules to catalyze the ORR process. The reduced oxygen species are then either directly released into the electrolyte or interacted with the reduced TEMPO moieties, which are then chemically quenched by the PDI backbone to generate $\mathrm{Li}_{2} \mathrm{O}_{2}$ nanoparticles. Therefore, the entire discharge process is mainly driven by the chemical quenching of $\mathrm{O}_{2}{ }^{\circ}$ in the electrolyte, which has also been verified by a rotating ring-disk electrode (RRDE) measurements (Figure S19-20). ${ }^{59}$ The above process is further enhanced when carbon nanotube (CNT) electrodes with higher specific surface area are used to accelerate the formation of $\mathrm{O}_{2}{ }^{-{ }^{-}}$(Figure S21-24). The results clearly corroborate that PDI-TEMPO molecules can efficiently relay electrons from the electrode surface to the dissolved $\mathrm{O}_{2}$ to produce $\mathrm{O}_{2}{ }^{-}$. . Meanwhile, the $\mathrm{O}_{2}{ }^{-*}$ can be chemically disproportionated to $\mathrm{Li}_{2} \mathrm{O}_{2}$ with the assistance of PDI backbones simultaneously (Figure S25-26, and Supplementary Video).

\section{The charge behaviour of $\mathrm{Li}_{2} \mathrm{O}_{2}$ batteries with PDI-TEMPO molecules}

The PDI-TEMPO molecules can also function as a charging reaction redox mediator to efficiently improve the round-trip efficiency for $\mathrm{Li}_{-} \mathrm{O}_{2}$ batteries (Figure S27). As shown in Figure 2a and S28-29, the charge voltage has been significantly decreased to $3.7 \mathrm{~V}$ (compared with $4.2 \mathrm{~V}$ in bare DEGDME electrolyte). This result is consistent with the CV curves (Figure 1c), indicating that the redox reaction of PDI-TEMPO is responsible for the decrease of the charge over-potentials of the $\mathrm{Li}-\mathrm{O}_{2}$ cells.

To further analyze the discharge-charge process, galvanostatic intermittent titration technique (GITT) was conducted during the discharge and charge processes. As shown in Figure 3a, the discharge curves and 
the open circuit potentials in the PDI-TEMPO electrolyte are more stable than that in bare DEGDME electrolyte, owing to fast discharge kinetics in the PDI-TEMPO electrolyte. During charging, the equilibrium potentials of the cell with PDI-TEMPO electrolyte are much lower, ascribed to fast kinetics of $\mathrm{Li}_{2} \mathrm{O}_{2}$ decomposition in PDI-TEMPO electrolyte (Figure $3 \mathrm{~b}$ and S30). Moreover, the enlarged GITT curves in the bare DEGDME electrolyte show three distinguishable charge stages. ${ }^{11,60}$ The first stage $(0-0.15 \mathrm{mAh} \mathrm{cm}$

$\left.{ }^{2}\right)$ displays a linear increase of voltage during the charge scan, which could be ascribed to the delithiation of the $\mathrm{Li}_{2} \mathrm{O}_{2}$ in the initial charge process. The second stage $\left(0.15-0.35 \mathrm{mAh} \mathrm{cm}{ }^{-2}\right)$ presents a temporary increase but followed by a drop of the charge voltage during each charge scan, indicating a typical $\mathrm{Li}_{2} \mathrm{O}_{2}$ decomposition through the nucleation process. The third stage $\left(0.35-0.5 \mathrm{mAh} \mathrm{cm}{ }^{-2}\right)$ exhibits a flat increase of the voltage, which may originate from the mixed reactions of $\mathrm{Li}_{2} \mathrm{O}_{2}$ decomposition and parasitic reactions at high over-potential. The GITT curves in PDI-TEMPO, however, show no divided charge stages. A flat plateau is observed, without temporary increase of charge voltage at each charge step, owing to the lack of typical $\mathrm{Li}_{2} \mathrm{O}_{2}$ decomposition through the nucleation process. Therefore, the charge process in the $\mathrm{Li}-\mathrm{O}_{2}$ cell with PDI-TEMPO electrolyte proceeds through a different mechanism from those in the cell with bare DEGDME electrolyte. The charge process is triggered and accelerated by the chemical reaction between oxidized TEMPO moieties in PDI-TEMPO molecules and solid $\mathrm{Li}_{2} \mathrm{O}_{2}$, as well as the quenching reaction between PDI-TEMPO and released superoxide species. Therefore, it proves that PDI-TEMPO can efficiently accelerate the kinetics of the OER.

The charging reaction has been further studied by a quantitative in-situ differential electrochemical mass spectrometry (DEMS) using less volatile tetraethylene glycol dimethyl ether (TEGDME) electrolyte, during which the $\mathrm{O}_{2}$ evolved and the charge passed were monitored simultaneously. The oxygen evolution during the charge process with ether electrolyte has the same trend as the GITT results. A peak increase in the evolution at the initial stage is followed by a sharp decrease before the evolution increases again in the middle of the charge process (Figure 3c). This corresponds to a typical $\mathrm{Li}_{2} \mathrm{O}_{2}$ decomposition through a nucleation process. ${ }^{11,45,60}$ The oxygen evolution in the PDI-TEMPO electrolyte shows a steady curve from the initial stage of charge. It proves that the chemical reaction between the oxidized PDI-TEMPO and $\mathrm{Li}_{2} \mathrm{O}_{2}$ dominates the charge process (Figure $3 \mathrm{~d}$ ). The ratio of the charge passed and the $\mathrm{O}_{2}$ evolved during charging of the $\mathrm{Li}^{-} \mathrm{O}_{2}$ battery has been quantified to be $2.01 \mathrm{e}-/ \mathrm{O}_{2}$, while for bare $\mathrm{Li}-\mathrm{O}_{2}$ cell a 2.40 $\mathrm{e}^{-} / \mathrm{O}_{2}$ has been obtained. The enhanced charging reversibility confirms that PDI-TEMPO can also efficiently promote the charge process.

\section{PDI-TEMPO to suppress parasitic reactions}

The cycling performance of $\mathrm{Li}-\mathrm{O}_{2}$ cells containing PDI-TEMPO molecules has been dramatically improved (Figure 4a-b and S31-32), because PDI-TEMPO molecules act as an $\mathrm{O}_{2}{ }^{--}$quencher to eliminate active $\mathrm{O}_{2}{ }^{*-}$ species, and expedite both discharge and charge processes. Compared with only 39 cycles delivered by the $\mathrm{Li}_{-} \mathrm{O}_{2}$ cell with bare DEGDME electrolyte, the cell with PDI-TEMPO electrolyte has shown a stable cycling performance over 300 cycles (Figure 4b). As shown in Figure 4a, the cell with PDI-TEMPO 
electrolyte displays stable charge potentials around $3.7 \mathrm{~V}$ during cycling, which is about $0.7 \mathrm{~V}$ lower than the cell with bare DEGDME electrolyte. The excellent electrochemical performance should be ascribed to the unique functions of PDI-TEMPO, which can efficiently diminish parasitic reactions and promote discharge and charge processes. To prove this point, we performed post-mortem FTIR and XRD characterizations on the cathodes after cycling (Figure 4c-f). The discharge products were dominated by $\mathrm{Li}_{2} \mathrm{O}_{2}$ after the first discharge with PDI-TEMPO electrolyte, because strong FTIR peaks were found in the range of 400-700 nm and no peaks were spotted in the range of 1300-1700 nm in either electrolyte. These FTIR peaks disappeared after the first charge process, indicating highly reversible formation and decomposition of $\mathrm{Li}_{2} \mathrm{O}_{2}$ during discharge and charge processes. However, the FTIR peaks at 400-700 nm in bare DEGDME electrolyte remained in the charge process after 5 cycles, and the peaks associated with $\mathrm{Li}_{2} \mathrm{CO}_{3}$ in the range of $1300-1700 \mathrm{~nm}$ increased gradually with cycling (Figure $4 \mathrm{c}$ ). This confirms that a large quantity of $\mathrm{Li}_{2} \mathrm{CO}_{3}$ accumulated after several cycles in the bare DEGDME electrolyte. On the contrary, the FTIR peaks in the range of $400-700 \mathrm{~nm}$ reversibly appeared and disappeared after discharge and charge processes in PDI-TEMPO electrolyte, corroborating that $\mathrm{Li}_{2} \mathrm{O}_{2}$ is the dominant discharge product (Figure $4 \mathrm{~d}$ ). The XRD patterns of the corresponding cathodes also confirm the same conclusion. The XRD peaks of $\mathrm{Li}_{2} \mathrm{O}_{2}$ became weaker on cycling and eventually disappeared after 10 cycles when using bare DEGDME electrolyte (Figure 4e). The XRD peaks of $\mathrm{Li}_{2} \mathrm{O}_{2}$ remained visible after 25 cycles in PDI-TEMPO electrolyte (Figure 4f).

The accumulation of byproducts in the bare DEGDME electrolyte originates from parasitic reactions of active oxygen species $\left(\mathrm{O}_{2}{ }^{\cdot-}\right.$ and $\left.{ }^{1} \mathrm{O}_{2}\right)$ and the decomposition of electrolyte solvent. The continuous attack by $\mathrm{O}_{2}{ }^{-{ }^{-}}$and ${ }^{1} \mathrm{O}_{2}$ to solvent molecules and cathode materials lead to the formation of a substantial amount of byproducts during cycling. Moreover, high charging voltage is required to decompose both $\mathrm{Li}_{2} \mathrm{O}_{2}$ and byproducts, resulting in the further decomposition of electrolyte solvent and generation of more ${ }^{1} \mathrm{O}_{2}$. This vicious cycle continuously produces byproducts and eventually terminates the $\mathrm{Li}^{-} \mathrm{O}_{2}$ batteries. It is worth noting that adding TEMPO, a commonly used redox mediator, in the DEGDME electrolyte to lower the charge potential, can also suppress parasitic reactions associated with large over-potentials to certain extend during the charge process (and possibly accelerates the relaxation of ${ }^{1} \mathrm{O}_{2}$ ). ${ }^{45}$ However, we found that byproducts still quickly accumulated during cycling (Figure S33). This specifies that parasitic reactions related to active oxygen species attack during the discharge and charge process remained severe. The rational design of PDI-TEMPO molecules can efficiently lower the charge over-potentials and quench $\mathrm{O}_{2}{ }^{-{ }^{-}}$species, both of which are deemed as the origins of ${ }^{1} \mathrm{O}_{2}$ generation. Furthermore, TEMPO moieties are also reported to accelerate the relaxation of ${ }^{1} \mathrm{O}_{2}$ during the operation of $\mathrm{Li}-\mathrm{O}_{2}$ batteries. ${ }^{45}$ Therefore, PDI-TEMPO molecules are able to suppress the generation of ${ }^{1} \mathrm{O}_{2}$ as well, leading to the comprehensive suppression of parasitic reactions. To verify this assertion, we conducted a demonstration experiment by adding $20 \mathrm{mM}$ 9,10-dimethylanthracene (DMA) in electrolytes as the trap agent for ${ }^{1} \mathrm{O}_{2}$. The results in Figure $\mathrm{S} 34$ shows that DMA is quickly consumed in DEGDME electrolyte over cycling, while TEMPO electrolyte displays a much lower consumption rate of DMA. The consumption rate 
of DMA in PDI-TEMPO electrolyte is the slowest, which almost equals the self-degradation rate of DMA in $\mathrm{O}_{2}$ atmosphere. This result unambiguously verifies that PDI-TEMPO molecules can not only quench superoxide radicals and lower charge over-potentials, but also suppress the generation of ${ }^{1} \mathrm{O}_{2}$, leading to significantly reduced parasitic reactions.

\section{Cycling performance of $\mathrm{Li}^{-} \mathrm{O}_{2}$ batteries with PDI-TEMPO molecules}

Unlike previously reported redox mediators that can easily shuttle to the negative electrode and react with the highly active lithium metal, PDI-TEMPO molecules can effectively overcome this issue in $\mathrm{Li}^{-} \mathrm{O}_{2}$ batteries. Our rationally designed PDI-TEMPO molecules contain a conjugated PDI backbone and two bulky TEMPO moieties. The steric hindrance between these two segments results in a twisted stereostructure of PDI-TEMPO molecule, in which TEMPO moieties are not on the same plane as the PDI backbone (Figure 1 $\mathrm{b}$ and S35a-b). This distinctive stereostructure enables PDI-TEMPO molecules to be restricted in the cathode region by Van Der Waals forces via $\pi-\pi$ interactions between the conjugated PDI backbone and the conjugated graphitic carbon in the cathodes (Figure S35c). ${ }^{46,51,54}$ Meanwhile, such $\pi-\pi$ interactions are weakened by the steric hindrance between the graphitic carbon and bulky TEMPO moieties, preventing PDI-TEMPO molecules from depositing on the cathode (Figure 5a and S35c). Consequently, PDI-TEMPO molecules are still in the electrolyte, but prohibited from migrating to lithium anode and reacting with lithium metal. Moreover, since PDI-TEMPO molecules quench the reduced oxygen species immediately after they are generated, these species are also restricted to the cathode region to form discharge products (Figure S25). Therefore, PDI-TEMPO molecules can also strongly inhibit parasitic reactions on lithium metal anodes from these small molecules. To verify this, lithium metal anodes were characterized by SEM after cycling. A comparison experiment was conducted by dissolving $10 \mathrm{mM}$ TEMPO in DEGDME electrolyte. As shown in Figure S36, the lithium foil retrieved from TEMPO electrolyte is severely corroded, caused by the direct reactions between lithium metal and oxidized TEMPO molecules. The lithium foil in the bare DEGDME electrolyte also shows a corroded morphology (Figure 5b), which originates from the parasitic reactions between lithium metal and the dissolved small molecules such as oxygen species (Figure S37). On the contrast, the lithium foil in PDITEMPO electrolyte shows no obvious corrosion after cycling (Figure 5c), demonstrating that PDI-TEMPO molecules can suppress parasitic reactions caused by the dissolved oxygen species. Therefore, further increasing the concentration of PDI-TEMPO in the electrolyte until $10 \mathrm{mM}$ should not deteriorate the electrochemical performance (concentration optimization in Figure S38). Instead, high concentration of PDI-TEMPO enhances its capability for quenching $\mathrm{O}_{2}{ }^{*-}$ and suppressing ${ }^{1} \mathrm{O}_{2}$, especially at elevated current densities (Figure S39). Hence, we subsequently doubled the concentration of PDI-TEMPO to $10 \mathrm{mM}$ in electrolyte. As shown in Figure $5 \mathrm{~d}$, the $\mathrm{Li}^{-} \mathrm{O}_{2}$ cell with $10 \mathrm{mM}$ PDI-TEMPO electrolyte presents low overpotentials, and a significantly extended cycle life of more than 450 cycles (Figure $5 e$ and S40). We further incorporated a Nafion membrane on lithium metal to prevent the dendrite growth and a porous graphene electrode to accommodate more $\mathrm{Li}_{2} \mathrm{O}_{2}$ (Figure S41-43). The $\mathrm{Li}^{-} \mathrm{O}_{2}$ cell with PDI-TEMPO reagent has exhibited an ultralong cycle life exceeding 1400 cycles (Figure S44) ${ }^{61}$ 


\section{Conclusions}

A multifunctional PDI-TEMPO quencher has been rationally designed and synthesized for boosting the performance of $\mathrm{Li}_{-} \mathrm{O}_{2}$ batteries. The PDI-TEMPO molecule contains a PDI backbone with the capability of quenching $\mathrm{O}_{2}{ }^{\cdot-}$, and redox mediator-active TEMPO moieties to catalyze both discharge and charge processes in the electrolyte solution. When added in the DEGDME electrolyte, the operation of the $\mathrm{Li}^{-} \mathrm{O}_{2}$ cell undergoes a new chemical-quenching reaction mechanism in the PDI-TEMPO electrolyte, leading to the formation of $\mathrm{Li}_{2} \mathrm{O}_{2}$ nanoparticles. Furthermore, the unique twisted molecular structure confines PDITEMPO molecules in the cathode region, which can effectively prevent corrosion of lithium metal anodes. Consequently, $\mathrm{Li}_{-} \mathrm{O}_{2}$ cells containing PDI-TEMPO quencher demonstrated an increased discharge capacity, improved energy efficiency, diminished parasitic reactions, and long cycle life.

\section{Declarations}

\section{Acknowledgements}

We acknowledge Prof Yuhui Chen and Chuan Tan from Nanjing Tech University, Nanjing for their valuable discussions of in-situ DEMS. This project is financially supported by the Australian Research Council (ARC) through the ARC Discovery Project (DP160104340, DP170100436, DP180102297 and DP200101249) and ARC Discovery Early Career Researcher Award (DE180100036). Z.P. is credited to National Key R\&D Program of China (Project No. 2016YFB0100100 and 2018YFB0104400), National Natural Science Foundation of China (21972055, 21825202, 21575135, 21733012 and 21972133) and the Newton Advanced Fellowships (NAF/R2/180603). The work at Argonne National Laboratory was supported from the U. S. Department of Energy (DOE), Office of Energy Efficiency and Renewable Energy, Vehicle Technologies Office. Argonne National Laboratory is operated for DOE Office of Science by UChicago Argonne, LLC, under contract number DE-AC02-06CH11357.

\section{Author contributions}

J. Z., Y. Z. and G. W. conceived the idea. J. Z., A. T., Y. X. synthesized the PDI-TEMPO molecules. J. Z. and Y. Z. performed the electrochemical experiments. J. Z. and K. Y. performed experiments on lithium anode stability tests. J. Z., and Y. Z. performed EPR measurement. J. Z., Y. Z., S. W., X. G., and F. Q. conducted characterizations. B. S., A. M. M., P. H., H. Z., Z. P., and J. L. were all involved in discussions. All of the authors contributed to the writing to the manuscript before submission.

\section{Competing interests}

The authors declare no competing financial interests.

Data availability: The data that support the findings of this study are available from the corresponding authors upon reasonable request. 


\section{References}

1 Abraham, K. \& Jiang, Z. A polymer electrolyte-based rechargeable lithium/oxygen battery. J. Electrochem. Soc. 143, 1 (1996).

2 Xia, C., Kwok, C. \& Nazar, L. A high-energy-density lithium-oxygen battery based on a reversible four-electron conversion to lithium oxide. Science 361, 777-781 (2018).

3 Lu, J. et al. Aprotic and aqueous Li- $\mathrm{O}_{2}$ batteries. Chem. Rev. 114, 5611-5640 (2014).

4 Luntz, A. C. \& McCloskey, B. D. Nonaqueous Li-air batteries: a status report. Chem. Rev. 114, 1172111750 (2014).

5 Liu, T. et al. Current challenges and routes forward for nonaqueous lithium-air batteries. Chem. Rev. 120, 6558-6625 (2020).

6 Kwak, W.-J. et al. Lithium-oxygen batteries and related systems: potential, status, and future. Chem. Rev. 120, 6626-6683 (2020).

7 Peng, Z. et al. Oxygen Reactions in a Non-Aqueous Li Electrolyte. Angew. Chem. Int. Ed. 50, 63516355 (2011).

8 Zhang, Y. et al. Potential-dependent generation of $\mathrm{O}^{2-}$ and $\mathrm{LiO}_{2}$ and their critical roles in $\mathrm{O}_{2}$ reduction to $\mathrm{Li}_{2} \mathrm{O}_{2}$ in aprotic $\mathrm{Li}_{2} \mathrm{O}_{2}$ batteries. J. Phys. Chem. C 120, 3690-3698 (2016).

9 Kang, S., Mo, Y., Ong, S. P. \& Ceder, G. A facile mechanism for recharging $\mathrm{Li}_{2} \mathrm{O}_{2}$ in $\mathrm{Li}_{-} \mathrm{O}_{2}$ batteries. Chem. Mater. 25, 3328-3336 (2013).

10 Ganapathy, $\mathrm{S}$. et al. Nature of $\mathrm{Li}_{2} \mathrm{O}_{2}$ oxidation in a $\mathrm{Li}^{-} \mathrm{O}_{2}$ battery revealed by operando X-ray diffraction. J. Am. Chem. Soc. 136, 16335-16344 (2014).

11 Lu, Y.-C. \& Shao-Horn, Y. Probing the reaction kinetics of the charge reactions of nonaqueous $\mathrm{Li}^{-} \mathrm{O}_{2}$ batteries. J. Phys. Chem. Lett. 4, 93-99 (2013).

12 Wang, Y. \& Lu, Y.-C. Nonaqueous lithium-oxygen batteries: reaction mechanism and critical open questions. Energy Storage Mater. 28, 235-246 (2020).

13 Cao, R. et al. The mechanisms of oxygen reduction and evolution reactions in nonaqueous lithiumoxygen batteries. ChemSusChem 7, 2436-2440 (2014).

$14 \mathrm{Li}, \mathrm{F}$. \& Chen, J. Mechanistic evolution of aprotic lithium-oxygen batteries. Adv. Energy Mater. 7, 1602934 (2017). 
15 McCloskey, B. et al. Twin problems of interfacial carbonate formation in nonaqueous $\mathrm{Li}^{-} \mathrm{O}_{2}$ batteries. J. Phys. Chem. Lett. 3, 997-1001 (2012).

16 Ottakam Thotiyl, M. M., Freunberger, S. A., Peng, Z. \& Bruce, P. G. The carbon electrode in nonaqueous $\mathrm{Li}^{-} \mathrm{O}_{2}$ cells. J. Am. Chem. Soc. 135, 494-500 (2013).

17 Yao, X., Dong, Q., Cheng, Q. \& Wang, D. Why do lithium-oxygen batteries fail: parasitic chemical reactions and their synergistic effect. Angew. Chem. Int. Ed. 55, 11344-11353 (2016).

18 Johnson, $\mathrm{L}$. et al. The role of $\mathrm{LiO}_{2}$ solubility in $\mathrm{O}_{2}$ reduction in aprotic solvents and its consequences for $\mathrm{Li}_{2} \mathrm{O}_{2}$ batteries. Nat. Chem. 6, 1091 (2014).

19 Burke, C. M., Pande, V., Khetan, A., Viswanathan, V. \& McCloskey, B. D. Enhancing electrochemical intermediate solvation through electrolyte anion selection to increase nonaqueous $\mathrm{Li}-\mathrm{O}_{2}$ battery capacity. Proc. Natl. Acad. Sci. 112, 9293-9298 (2015).

20 Hwang, C. et al. Biomimetic superoxide disproportionation catalyst for anti-aging lithium-oxygen batteries. ACS Nano 13, 9190-9197 (2019).

21 Landa-Medrano, I. et al. Potassium salts as electrolyte additives in lithium-oxygen batteries. J. Phys. Chem. C121, 3822-3829 (2017).

22 Viswanathan, $\mathrm{V}$. et al. Electrical conductivity in $\mathrm{Li}_{2} \mathrm{O}_{2}$ and its role in determining capacity limitations in non-aqueous $\mathrm{Li}^{-} \mathrm{O}_{2}$ batteries. J. Chem. Phys. 135, 214704 (2011).

23 McCloskey, B. D., Burke, C. M., Nichols, J. E. \& Renfrew, S. E. Mechanistic insights for the development of $\mathrm{Li}-\mathrm{O}_{2}$ battery materials: addressing $\mathrm{Li}_{2} \mathrm{O}_{2}$ conductivity limitations and electrolyte and cathode instabilities. Chem. Commun. 51, 12701-12715 (2015).

24 Chen, Y., Freunberger, S. A., Peng, Z., Fontaine, O. \& Bruce, P. G. Charging a Li-O $\mathrm{O}_{2}$ battery using a redox mediator. Nat. Chem. 5, 489 (2013).

25 Sun, D. et al. A solution-phase bifunctional catalyst for lithium-oxygen batteries. J. Am. Chem. Soc. 136, 8941-8946 (2014).

26 Kundu, D., Black, R., Adams, B. \& Nazar, L. F. A highly active low voltage redox mediator for enhanced rechargeability of lithium-oxygen batteries. ACS Cent. Sci. 1, 510-515 (2015).

27 Liu, T. et al. Cycling $\mathrm{Li}_{-} \mathrm{O}_{2}$ batteries via LiOH formation and decomposition. Science 350, 530-533 (2015).

28 Kwak, W.-J. et al. $\mathrm{Li}-\mathrm{O}_{2}$ cells with $\mathrm{LiBr}$ as an electrolyte and a redox mediator. Energy Environ. Sci. 9, 2334-2345 (2016). 
29 Matsuda, S. et al. Cobalt phthalocyanine analogs as soluble catalysts that improve the charging performance of $\mathrm{Li}^{-} \mathrm{O}_{2}$ batteries. Chem. Phys. Lett. 620, 78-81 (2015).

30 Lim, H.-D. et al. Superior rechargeability and efficiency of lithium-oxygen batteries: Hierarchical air electrode architecture combined with a soluble catalyst. Angew. Chem. Int. Ed. 53, 3926-3931 (2014).

31 Guo, Z., Li, C., Liu, J., Wang, Y. \& Xia, Y. A Long-life lithium-air battery in ambient air with a polymer electrolyte containing a redox mediator. Angew. Chem. Int. Ed. 56, 7505-7509 (2017).

32 Adams, B. D. et al. Towards a stable organic electrolyte for the lithium oxygen battery. Adv. Energy Mater. 5, 1400867 (2015).

33 Peng, Z., Freunberger, S. A., Chen, Y. \& Bruce, P. G. A reversible and higher-rate Li- $\mathrm{O}_{2}$ battery. Science 337, 563-566 (2012).

34 Kim, B. G. et al. Ordered mesoporous titanium nitride as a promising carbon-free cathode for aprotic lithium-oxygen batteries. ACS Nano 11, 1736-1746 (2017).

35 Luo, W.-B., Pham, T. V., Guo, H.-P., Liu, H.-K. \& Dou, S.-X. Three-dimensional array of TiN@Pt 3 Cu nanowires as an efficient porous electrode for the lithium-oxygen Battery. ACS Nano 11, 1747-1754 (2017).

36 Gao, X., Chen, Y., Johnson, L. R., Jovanov, Z. P. \& Bruce, P. G. A rechargeable lithium-oxygen battery with dual mediators stabilizing the carbon cathode. Nat. Energy 2, 17118 (2017).

37 Gao, X., Chen, Y., Johnson, L. \& Bruce, P. G. Promoting solution phase discharge in $\mathrm{Li}^{\mathrm{i}} \mathrm{O}_{2}$ batteries containing weakly solvating electrolyte solutions. Nat. Mater. 15, 882-888 (2016).

38 Ryu, W.-H. et al. Heme biomolecule as redox mediator and oxygen shuttle for efficient charging of lithium-oxygen batteries. Nat. Commun. 7, 1-10 (2016).

39 Zhang, J. et al. A versatile functionalized ionic liquid to boost the solution-mediated performances of lithium-oxygen batteries. Nat. Commun. 10, 1-10 (2019).

40 Tkacheva, A. et al. TEMPO-ionic liquids as redox mediators and solvents for $\mathrm{Li}^{-} \mathrm{O}_{2}$ batteries. J. Phys. Chem. C124, 5087-5092 (2020).

41 Zhang, Y. et al. High-capacity and high-rate discharging of a coenzyme Q10-catalyzed Li- $\mathrm{O}_{2}$ battery. Adv. Mater. 30, 1705571 (2018).

42 Bergner, B. J., Schürmann, A., Peppler, K., Garsuch, A. \& Janek, J. r. TEMPO: a mobile catalyst for rechargeable $\mathrm{Li}_{-} \mathrm{O}_{2}$ batteries. J. Am. Chem. Soc. 136, 15054-15064 (2014). 
43 Kim, B. G., Kim, S., Lee, H. \& Choi, J. W. Wisdom from the human eye: a synthetic melanin radical scavenger for improved cycle life of $\mathrm{Li}^{-} \mathrm{O}_{2}$ battery. Chem. Mater. 26, 4757-4764 (2014).

44 Kwak, W.-J. et al. Mutual conservation of redox mediator and singlet oxygen quencher in lithiumoxygen batteries. ACS Catal. 9, 9914-9922 (2019).

45 Liang, Z., Zou, Q., Xie, J. \& Lu, Y.-C. Suppressing singlet oxygen generation in lithium-oxygen batteries with redox mediators. Energy Environ. Sci. 13, 2870-2877 (2020).

46 Jalilov, A. S. et al. Perylene diimide as a precise graphene-like superoxide dismutase mimetic. ACS Nano 11, 2024-2032 (2017).

47 Nakatsuji, S. i. et al. Spin-carrying naphthalenediimide and perylenediimide derivatives. Bull. Chem. Soc. Japan 83, 1079-1085 (2010).

48 Colvin, M. T. et al. Competitive electron transfer and enhanced intersystem crossing in photoexcited covalent TEMPO-perylene-3, 4: 9, 10-bis (dicarboximide) dyads: unusual spin polarization resulting from the radical- triplet interaction. J. Phys. Chem. A 114, 1741-1748 (2010).

49 Mahne, N. et al. Singlet oxygen generation as a major cause for parasitic reactions during cycling of aprotic lithium-oxygen batteries. Nat. Energy 2, 1-9 (2017).

50 Mourad, E. et al. Singlet oxygen from cation driven superoxide disproportionation and consequences for aprotic metal- $\mathrm{O}_{2}$ batteries. Energy Environ. Sci. 12, 2559-2568 (2019).

51 Datar, A., Balakrishnan, K. \& Zang, L. One-dimensional self-assembly of a water soluble perylene diimide molecule by pH triggered hydrogelation. Chem. Commun. 49, 6894-6896 (2013).

52 Zhang, J., Sun, B., Xie, X., Zhao, Y. \& Wang, G. A bifunctional organic redox catalyst for rechargeable lithium-oxygen batteries with enhanced performances. Adv. Sci. 3, 1500285 (2016).

53 Guo, W., Yin, Y.-X., Xin, S., Guo, Y.-G. \& Wan, L.-J. Superior radical polymer cathode material with a two-electron process redox reaction promoted by graphene. Energy Environ. Sci. 5, 5221-5225 (2012).

54 Wu, D. et al. Perylene diimide-diamine/carbon black composites as high performance lithium/sodium ion battery cathodes. J. Mater. Chem. A 6, 13613-13618 (2018).

55 Black, R. et al. The Nature and impact of side reactions in glyme-based sodium-oxygen batteries. ChemSusChem 9, 1795-1803 (2016).

56 Aetukuri, N. B. et al. Solvating additives drive solution-mediated electrochemistry and enhance toroid growth in non-aqueous $\mathrm{Li}^{-} \mathrm{O}_{2}$ batteries. Nat. Chem. 7, 50-56 (2015). 
57 Aurbach, D., McCloskey, B. D., Nazar, L. F. \& Bruce, P. G. Advances in understanding mechanisms underpinning lithium-air batteries. Nat. Energy 1, 16128 (2016).

58 Zhang, Y. et al. Amorphous $\mathrm{Li}_{2} \mathrm{O}_{2}$ : chemical synthesis and electrochemical properties. Angew. Chem. Int. Ed. 55, 10717-10721 (2016).

59 Zhao, Y. et al. Cobalt-doped $\mathrm{MnO}_{2}$ ultrathin nanosheets with abundant oxygen vacancies supported on functionalized carbon nanofibers for efficient oxygen evolution. Nano Energy 54, 129-137 (2018).

60 Wang, Y. et al. A solvent-controlled oxidation mechanism of $\mathrm{Li}_{2} \mathrm{O}_{2}$ in lithium-oxygen batteries. Joule 2, 2364-2380 (2018).

61 Liang, Z., Zhou, Y. \& Lu, Y.-C. Dynamic oxygen shield eliminates cathode degradation in lithiumoxygen batteries. Energy Environ. Sci. 11, 3500-3510 (2018).

Figures

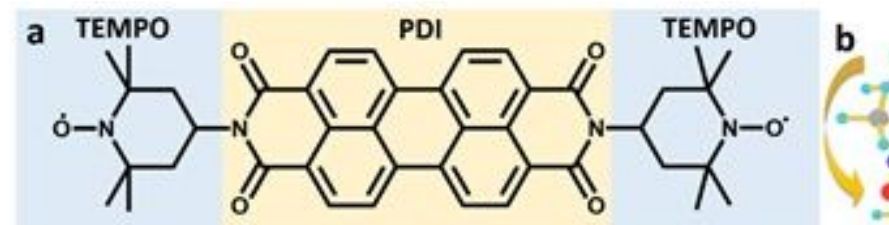

Redox mediator Superoxide radical quencher Redox mediator twist
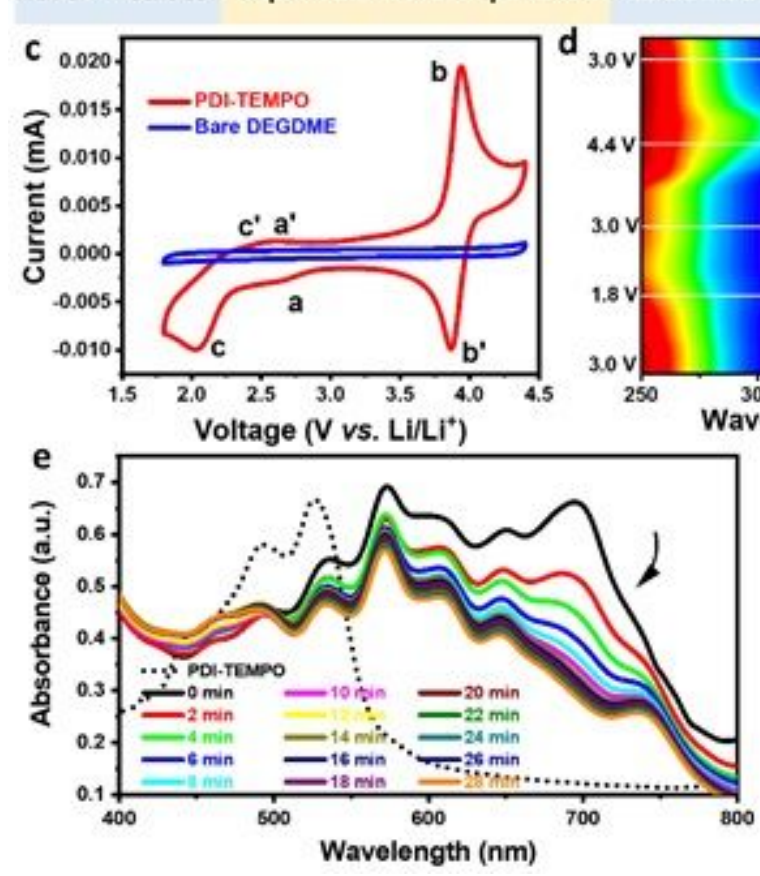
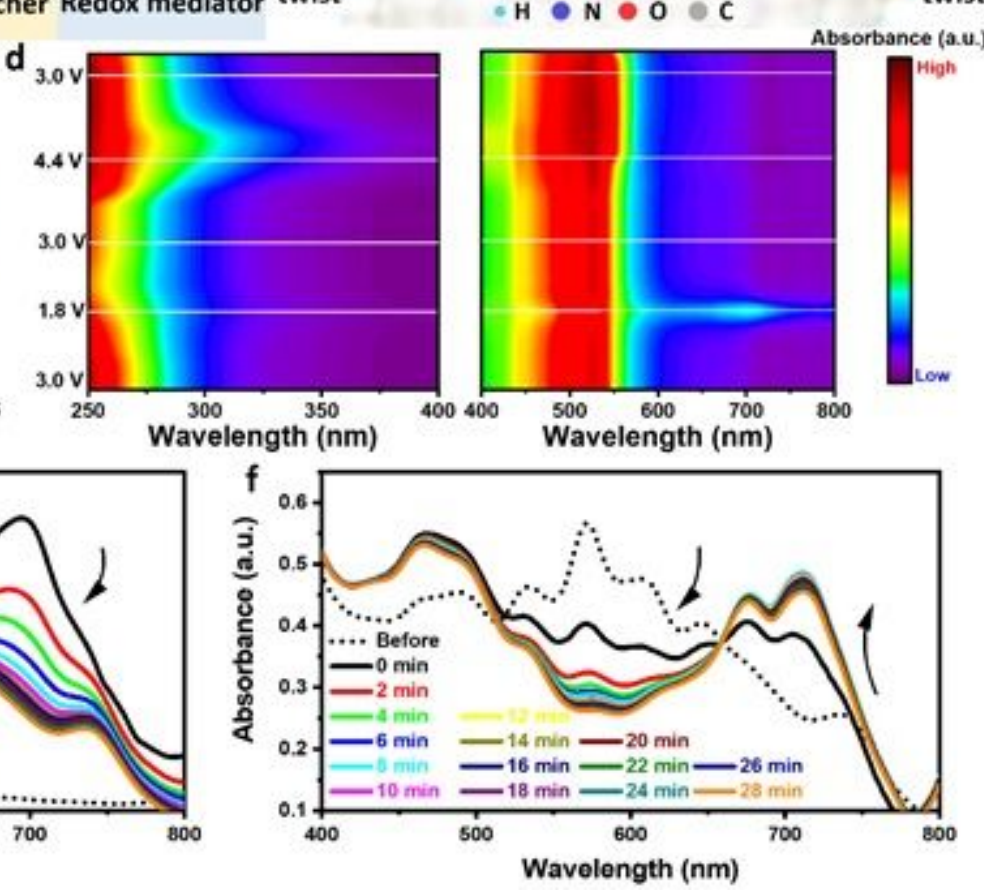

Figure 1

Investigation of the redox capability of PDI-TEMPO in electrolytes. a. The molecular structure and $b$. stereostructure of PDI-TEMPO. c. CV curves of three-electrode cells with and without PDI-TEMPO in the 
DEGDME electrolyte in an argon atmosphere. The scan rate is $100 \mathrm{mV} \mathrm{s}-1$. The concentration of PDITEMPO is $5 \mathrm{mM}$. d. In-situ UV-Vis spectra of the electrolyte with PDI-TEMPO scanned in the range from $1.8 \mathrm{~V}$ to $4.4 \mathrm{~V}$. e-f. UV-Vis spectra of the KO2-saturated DMSO solution with PDI-TEMPO e. before and $\mathrm{f}$. after the addition of lithium salt. The marked PDI-TEMPO spectrum in e is the original PDI-TEMPO/DMSO solution.

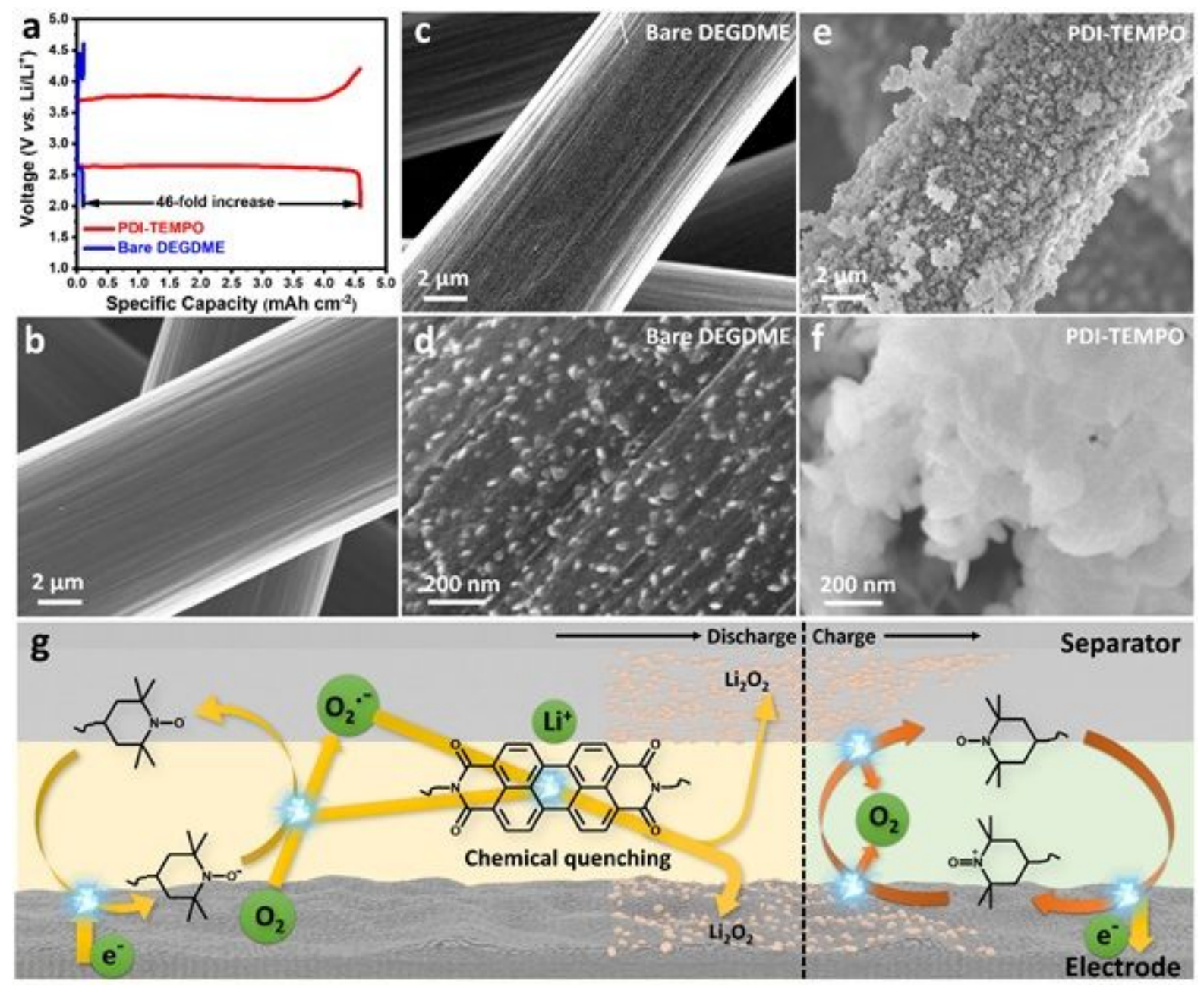

Figure 2

The improvement of $\mathrm{Li}-\mathrm{O} 2$ batteries with the aid of PDI-TEMPO. a. Full discharge-charge profiles of Li-O2 batteries with PDI-TEMPO electrolyte and bare DEGDME electrolyte. Lithium foils are used as the anodes, and carbon papers as the cathodes. The current density is $0.1 \mathrm{~mA} \mathrm{~cm}-2$. The concentration of PDI-TEMPO is $5 \mathrm{mM}$. SEM images of the carbon paper electrodes $b$. before and $c-f$. after the first discharge. The electrolytes used are c-d. bare DEGDME electrolyte and e-f. PDI-TEMPO electrolyte. g. Schematic illustration of the PDI-TEMPO facilitating the formation and decomposition of $\mathrm{Li} 2 \mathrm{O} 2$ during the operation of Li-O2 batteries. 

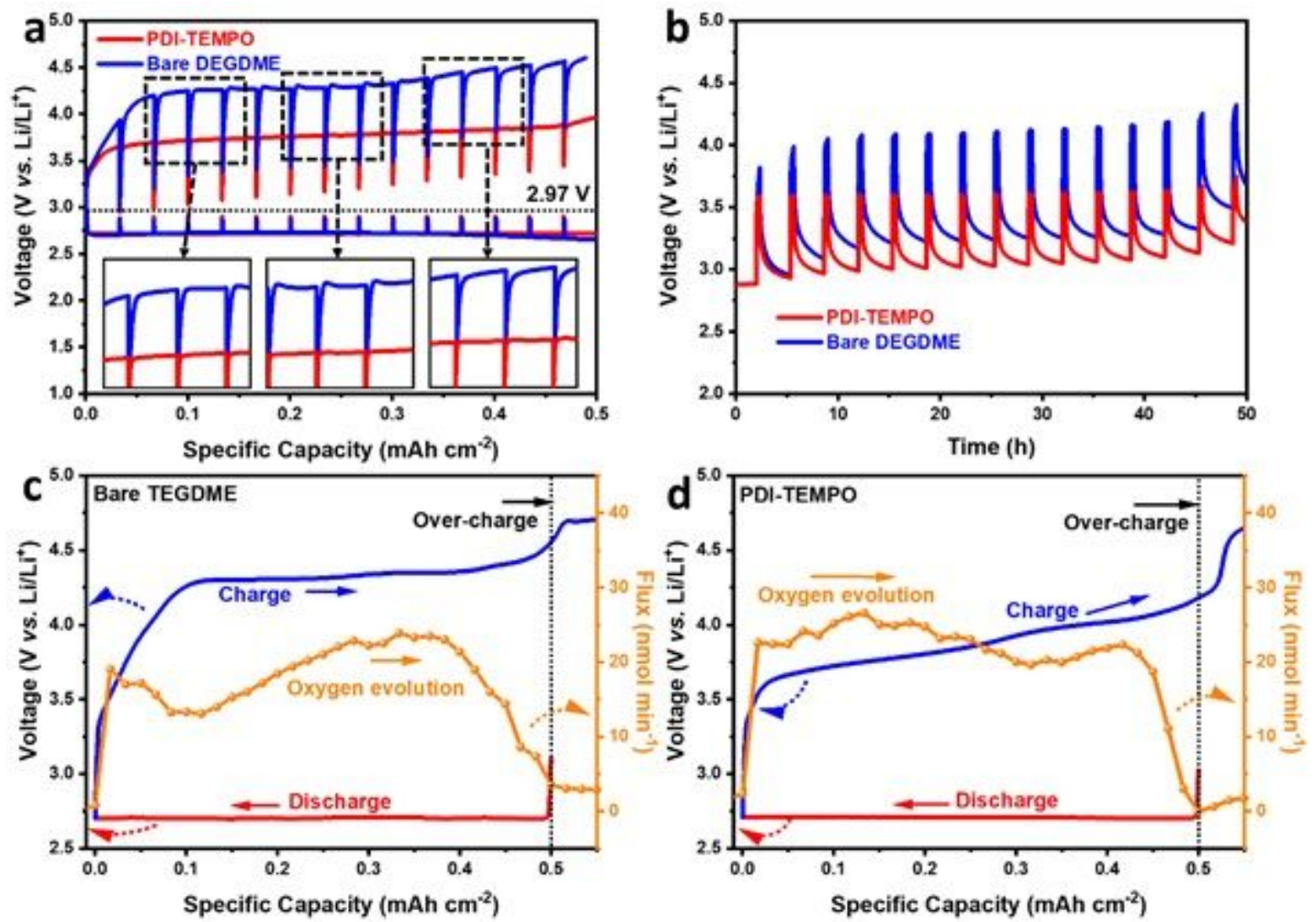

Figure 3

Investigation of mechanisms within Li-O2 batteries using PDI-TEMPO electrolyte. a-b. GITT curves of the Li-02 batteries, which were acquired with a current density of $0.1 \mathrm{~mA} \mathrm{~cm}-2$ for $0.5 \mathrm{mAh} \mathrm{cm}-2$ and a. a 60 min or b. a 180 min time interval during the discharge and $b$. charge processes. The insets are the enlarged images of selected areas. The concentration of PDI-TEMPO is $5 \mathrm{mM}$. c-d. In situ DEMS analysis of the gas evolution during the charge process of $\mathrm{Li}-\mathrm{O} 2$ cell operation with $\mathrm{c}$. bare TEGDME electrolyte and d. PDI-TEMPO electrolyte. The current density is $0.1 \mathrm{~mA} \mathrm{~cm}-2$.
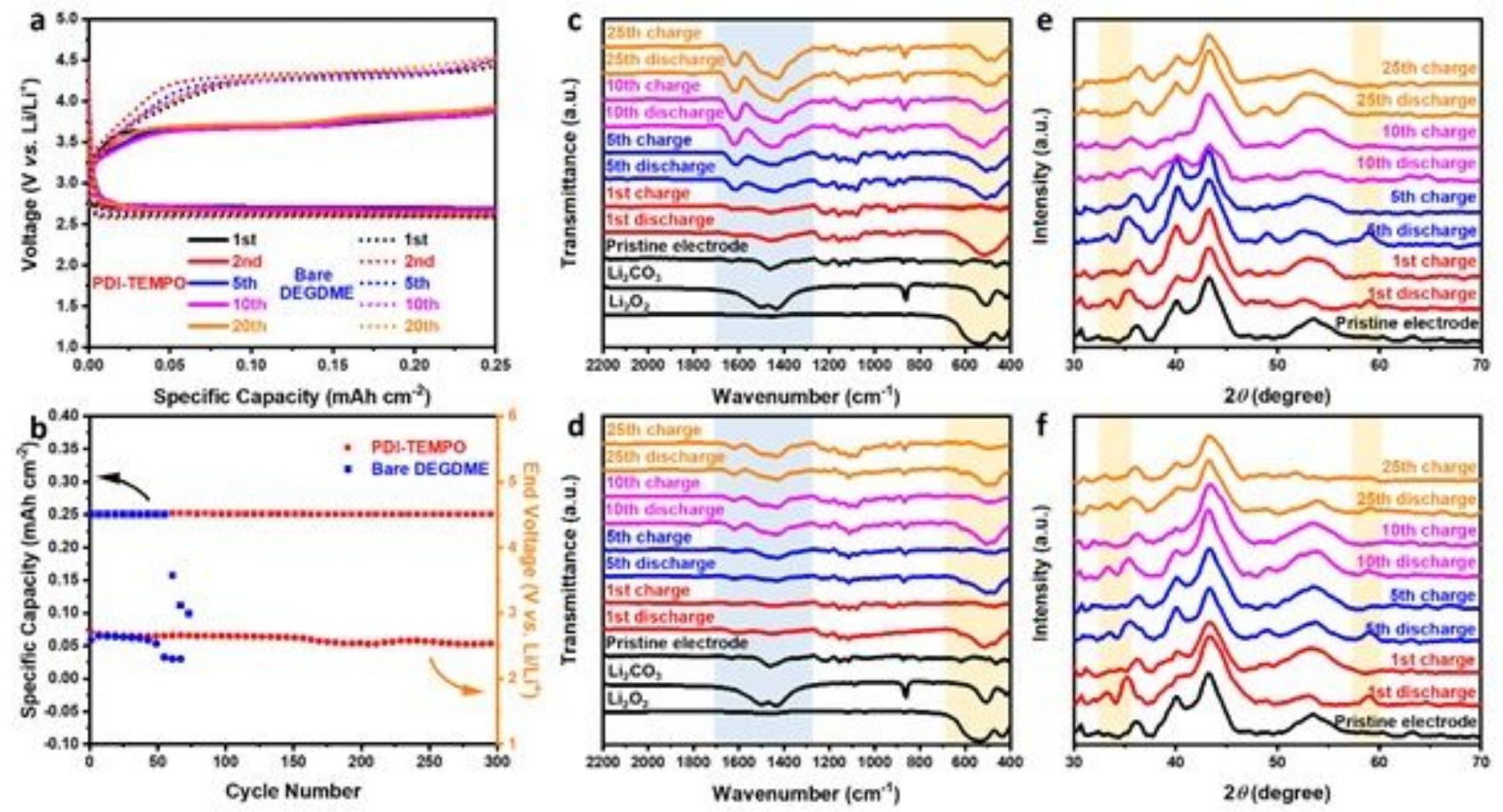


\section{Figure 4}

Post-mortem characterizations of electrodes after cycling. a. The discharge-charge profiles and $b$. cycling performance of Li-O2 batteries with PDI-TEMPO electrolyte and DEGDME electrolyte. The reversible capacities are restricted to $0.25 \mathrm{mAh} \mathrm{cm}-2$. The current densities are $0.1 \mathrm{~mA} \mathrm{~cm}-2$, and the cut-off voltage is $2.3 \mathrm{~V} / 4.6 \mathrm{~V}$. The concentration of PDI-TEMPO is $5 \mathrm{mM}$. c-d. Post-mortem FTIR spectra of electrodes after cycling with c. bare DEGDME electrolyte and d. PDI-TEMPO electrolyte. e-f. The post-mortem XRD patterns of the electrodes after cycles with e. bare DEGDME electrolyte and f. PDI-TEMPO electrolyte. The highlighted blue areas are the places where the characteristic peaks for Li2 $\mathrm{CO} 3$ appear, and the highlighted orange areas are the places where the characteristic peaks for Li2O2 appear.
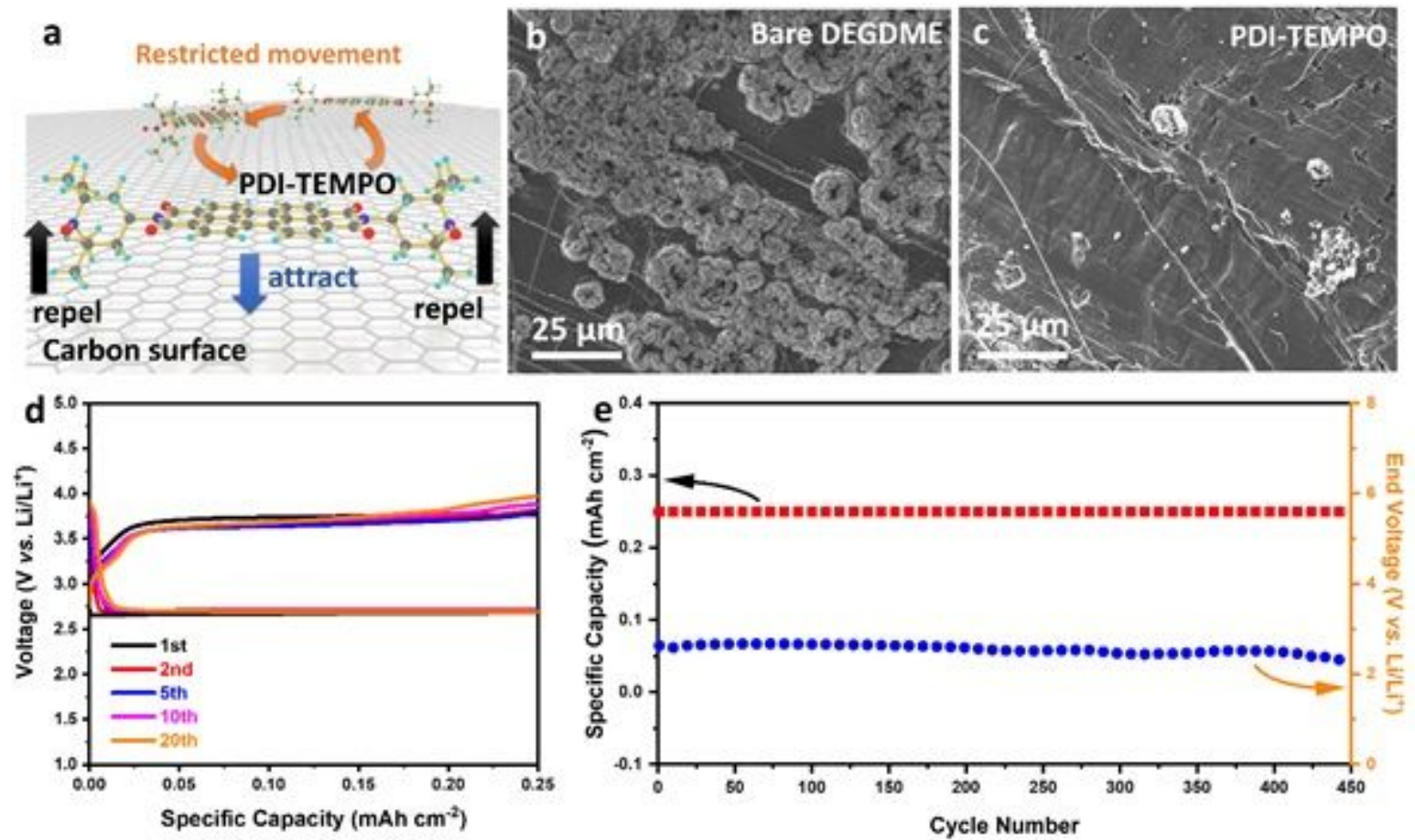

Figure 5

Influences of PDI-TEMPO on lithium metal anode and cycling performance. a. The schematic illustration of the interaction between PDI-TEMPO and graphitic carbon. b-c. The SEM images of the lithium metal anodes from b. bare DEGDME electrolyte and c. PDI-TEMPO electrolyte after 10 cycles. $d$. The dischargecharge profiles and e. cycling performance of the Li-O2 batteries with PDI-TEMPO electrolyte with $10 \mathrm{mM}$ PDI-TEMPO electrolyte. The current density is $0.2 \mathrm{mAh} \mathrm{cm}-2$.

\section{Supplementary Files}

This is a list of supplementary files associated with this preprint. Click to download.

- SupplementaryVideo.mp4

- Supplementarylnformation.docx 